\title{
A INSUBORDINAÇÃO CRIATIVA NA FORMAÇÃO CONTÍNUA DO PEDAGOGO PARA O ENSINO DA MATEMÁTICA: OS SUBALTERNOS FALAM?
}

\section{THE CREATIVE INSUBORDINATION IN THE CONTINUOUS TRAINING OF THE PEDAGOGUE FOR THE TEACHING OF MATHEMATICS: DO THE SUBALTERNS SPEAK?}

\author{
Maria José Costa dos Santos \\ Programa de pós-graduação em Educação - PPGE/UFC, mazzesantos@ufc.br \\ Fernanda Cíntia Costa Matos \\ Programa de pós-graduação em Educação - PPGE/UFC, cintiamatos@alu.ufc.br
}

\section{Resumo}

A formação de professores seja ela inicial ou continuada deve ser desenvolvida com foco nos processos de ensino e de aprendizagem de forma teórica e prática, ou como assinala Freire (1987) pela práxis. Esse texto visa apresentar a metodologia Sequência Fedathi (SF) e a Teoria Cultural da Objetivação (TO) como propostas de formação do docente que leciona matemática na educação básica. Para tanto, foi necessário: (a) análise da literatura sobre essas temáticas; e, (b) reflexões sobre práticas reflexivas de formação docente, com vistas a se pensar em que medida os subalternos falam visando manifestações de insubordinação criativa sobre o currículo e avaliação em movimento. As reflexões apontam para a necessidade de um profundo e amplo estudo sobre as consequências nefastas de uma formação que não prime pela autonomia e criatividade na ação docente, limitando sua práxis no espaço pedagógico.

Palavras-chave: Metodologia Sequência Fedathi. Teoria Cultural da Objetivação. Insubordinação Criativa. Formação inicial e contínua. Currículo de Matemática.

\section{Abstract}

Teacher formation, whether initial or continuing, should be developed with a focus on teaching and learning processes in a theoretical and practical way, or as Freire (1987) points out by praxis. This paper aims to present the methodology Fedathi Sequence (SF) and Cultural Theory of Objectivation (OT) as proposals for teacher Formation that teaches mathematics in basic education. Therefore, it was necessary to: (a) analyze the literature on these issues; And (b) reflections on reflexive practices of teacher formation, with a view to considering to what extent the subalterns speak aiming at manifestations of creative insubordination on the curriculum and evaluation in movement. The reflections point to the necessity of a deep and ample study on the harmful consequences of a formation that does not prime for the autonomy and creativity in the teaching action, limiting its praxis in the pedagogical space.

Key words: Fedathi Sequence Methodology. Cultural Theory of Objectification. Creative Insubordination. Initial and continuous Formation. Mathematics curriculum. 


\section{Introdução}

Entre os processos de Ensino e de Aprendizagem existem alguns paradigmas a serem superados, para que a educação em seus sentidos didático, epistemológico, sóciohistórico, dialético, ultrapasse as lacunas em sala de aula, especialmente nas salas de aulas de Matemática na Educação Básica. Para tanto, é necessário que na formação de professores seja ela inicial ou contínua se desenvolva os processos de ensino e a aprendizagem de forma teórica e prática, ou como assinala Freire (1987) a práxis. Para Dias (2016, p. 18) o Ensino e a Aprendizagem são dois processos distintos "[...] quero reafirmar que são dois processos e que cada um deles precisa ser compreendido/estudado/analisado como diferente, ainda que sejam interdisciplinares e complementares/imbricados".

Nesse texto apresentamos uma proposta de formação docente que envolve duas metodologias, de um lado uma preocupa-se com o trabalho do professor - o ensino, no caso a metodologia de ensino Sequência Fedathi, de Borges Neto (SOUSA, et al. 2013), de outro lado a Teoria Cultural da Objetivação, de Luís Radford, (RADFORD, 2015) a qual centra-se com mais entusiasmo sobre a aprendizagem. Adotamos nesse estudo que ensino e aprendizagem não são palavras compostas e se diferenciam em sua essência, pois ambas possuem estudos e teorias aplicáveis diferenciadas. Nisso, é preciso entender que o ensino e a aprendizagem são elementos essenciais da educação escolar, e que, portanto, ao discutir educação de qualidade eles não devem se desconectar, mas devem ser observados, subversivamente, de forma responsável, a fim de possibilitar manifestações de insubordinações criativas (D’Ambrosio, 2015) apoiadas na práxis (FREIRE, 1987).

Objetivamos apresentar a metodologia Sequência Fedathi e a Teoria Cultural da Objetivação, alinhadas a insubordinação criativa, como proposta de formação inicial ou contínua de professores que lecionam matemática no ensino fundamental nos anos iniciais por entender que a formação docente é um espaço de criação em permanente movimento. Para tanto analisamos pesquisas sobre as metodologias em questão, e planejamos uma sessão didática (VER APÊNDICE), como proposta de insubordinação criativa na matemática do ensino fundamental dos anos iniciais.

Esse texto é composto por essa seção que trata da introdução (apresentação e justificativa da temática), seguida de outras seções que fundamentam o objeto de estudo, seguidas pelas considerações e referências. A seção seguinte apresenta a SF e a TO.

\section{Ensino e Aprendizagem de matemática: metodologia Sequência Fedathi e Teoria Cultural da Objetivação}

Para apresentar a Metodologia da Sequência Fedathi-SF usamos Sousa et. al. (2013) e Santos (2007), já para apresentar a Teoria Cultural da Objetivação-TO, usamos Radford $(2014,2015)$. A SF é uma metodologia de ensino que segundo Sousa et al (2013), trabalha a partir de sessões didáticas que direciona o aluno/estudante agir como protagonista, isto é, o aluno deve ser atuante e participante direto de seu aprendizado, e o professor tem o papel de mediação antes, durante e depois das sessões didáticas para 
que o aluno não se sinta isolado desse processo. É importante que o aluno perceba que o professor planejou sua prática docente, e com seu auxílio o executou, e avaliará os resultados, a fim de prosseguir com o ensino ou refazer o processo.

A SF centra-se no ensino, e, portanto tem como principal ator - o professor, pois compreende que a postura docente frente aos alunos faz toda diferença na hora da aprendizagem, dependendo de como o professor propõe as atividades, o aluno se sente mais seguro para ousar e este obtém melhores respostas dos alunos. A SF acontece em quatro etapas, que podem ou não acontecerem de forma linear, como também nem sempre se realizam dentro de uma única aula, pois para a SF é importante considerar o tempo de aprendizagem do aluno.

As etapas da Sequência Fedathi são: a primeira é a Tomada de Posição - nessa etapa, o professor exibe o problema para o aluno, partindo de uma situação generalizável, ou seja, de uma circunstância possível de ser abstraída de seu contexto particular, para um modelo matemático genérico. Nessa fase o professor discute o acordo didático (normas de convivência durante o trabalho em sala) e trabalha o plateau (nivelamento dos conhecimentos prévios sobre o conteúdo em questão).(SOUSA ET ALL, 2013)

A segunda etapa é a Maturação - essa etapa é destinada a discussão entre o professor e os alunos a respeito da situação-problema apresentada; os alunos devem buscar compreender o problema e tentar identificar os possíveis caminhos que possam levá-lo a solução. Assim, feitas suas interpretações, deverão identificar quais os dados contidos no problema, qual a relação entre eles e o que está sendo solicitada pela atividade. A terceira etapa, que é a Solução - os alunos deverão organizar e apresentar modelos que possam conduzi-los a encontrar o que está sendo solicitado pelo problema; esses modelos podem ser em linguagem escrita / matemática ou simplesmente por intermédio de desenhos, gráficos, esquemas e até mesmo de verbalizações. Já quarta etapa, a Prova - é a etapa logo após as discussões, embates, debates realizados a respeito das soluções encontradas pelos alunos (individual ou coletivamente), o professor deverá apresentar o novo conhecimento como meio prático, a fim de otimizar para mediar a resposta do problema. (SOUSA ET AL 2013, p. 22-33)

As etapas da SF são sequências do trabalho docente, propostas ao professor para o trabalho pedagógico em sala de aula, mas o professor precisa e deve ser subversivo/ insubordinado, pois não necessariamente deve segui-las em ordem, elas podem acontecer de forma aleatória, criativa, responsável, a fim de satisfazer o propósito pedagógico para aquele evento - a aprendizagem.

Já a Teoria Cultural da Objetivação (TO), se preocupa mais com a aprendizagem que com o ensino, e visa uma relação desses processos de forma humanizada, pensando no ser cultural e na relação professor - aluno que não deve ser hierarquizada, pois visa à criação dialética de sujeitos reflexivos e éticos, de forma coletiva e colaborativa. Inicialmente conforme Radford (2015), foi uma teoria pensada para o ensino da matemática com a finalidade de despertar para um trabalho político com vistas a formar sujeitos éticos, humanizados, culturais e que estão permanentemente em evolução, para Radford (2015, p. 549) 
A teoria da objetivação - ensino e da aprendizagem. Esta teoria concebe a educação matemática como incorporada em um projeto educacional, transformacional maior. Ela postula o objetivo da Educação Matemática como um empreendimento dinâmico político, social, histórico e cultural voltado para a criação dialética de sujeitos reflexivos e éticos que se posicionam criticamente em discursos e práticas matemáticas, historicamente e culturalmente constituídas e sempre em evolução. (TRADUÇÃO NOSSA).

As bases teóricas que sustentam a TO estão em parte pautadas na Teoria sociointeracionista de Vygotsky (2001) com foco no trabalho e no sujeito como históricocultural e do materialismo dialético histórico com bases filosóficas em Marx. A TO reforça a importância de o professor estar no meio do processo de aprendizagem juntamente ao aluno, e vai contra ao construtivismo no sentido do afastamento do professor do processo de aprendizagem, pois entende que para que ocorra a aprendizagem, o professor também deve estar imerso na situação de aprendizagem, e não pode deixar essa ação apenas a cargo dos alunos, e nesse sentido, apresenta a TO à luz dos pressupostos da teoria de sociointeracionista de Vygotsky $(2001,2002)$.

Tanto a SF como a TO, entendem a importância do professor para o sucesso do aluno. Mas enquanto uma (SF) concebe aprendizagem e ensino como dois processos distintos e centra-se no ensino a outra (TO) entende que são indissociáveis, pois ocorrem simultaneamente, sendo que, na sala de aula para a SF o professor é o mediador do saber e para a TO, professor e aluno tem o mesmo papel na construção do saber, sem hierarquia, mas de modo dialético. Para a TO o professor é o organizador do ambiente de aprendizagem, mas não o sujeito principal.

A partir dessa reflexão, como a insubordinação criativa pode aparecer como elemento desencadeador da rotina pedagógica apresentando possibilidades de inovação e subversão responsável do currículo prescrito?

Com esse entendimento, a SF e a TO são apresentadas como propostas de formação docente com vistas a estabelecer relações entre uma formação matemática subversiva responsável a partir da insubordinação criativa, face às novas demandas exigidas para a formação matemática de qualidade do professor que leciona matemática na educação básica. E sobre essa formação ser pautada pela insubordinação criativa, D'Ambrosio e Lopes (2015) apontam que legitimação se dá pela centralização das práticas pedagógicas em bases éticas, ou seja, o professor deve ousar, mas com responsabilidade.

A Teoria Cultural da Objetivação foi pensada e idealizada pelo professor Luís Radford, que é professor da Laurentian University no Canadá, e possui várias extensões de pesquisas por vários países, e no Canadá, o professor Luís Radford, acompanha em escolas alguns grupos de pesquisas com sua teoria na prática. Já a Sequência Fedathi foi desenvolvida em meados dos anos de 1990, pelo educador matemático Hermínio Borges Neto, a partir da necessidade de preparar professores para aprender a ensinar matemática de forma mais significativa e criativa, fugindo dos padrões e currículos tradicionais de matemática, impostos pelas reformas do currículo de matemática em destaque internacional nas últimas décadas, com ênfase maior com o Movimento da Matemática Moderna, a partir dos anos 1950-1960, nos Estados Unidos da América-USA. 
Incomodados por esse movimento, alguns professores a fim de romper com o que estava posto, ousam aprofundar os estudos na área da Educação Matemática, lançam pesquisas e se reúnem em vários eventos espalhados pelo país para criticar esse currículo que apenas serviria ao mercado, sem atender a realidade de países em desenvolvimento, como o Brasil. A professora Martha Maria de Souza Dantas em um congresso na Bahia em 1955, diz

(...)Quanto aos programas, devemos fugir, por certo, das reformas que deformam. Uma reforma não se faz num dia: reformar o que está mal feito, sem estudar-Ihe realmente a estrutura e sem conhecer as nossas necessidades reais, seria talvez piorar. (...) Deixemos de copiar o estrangeiro porque não the podemos copiar o clima, a raça, as condições sociais, a formação. Sintamos melhor as nossas necessidades, não trancados em gabinetes de trabalho, como técnicos sem alma, e, sim, nesse contato humano que deve existir entre mestre e aluno.(...). (ANAIS EVENTO, 1955, p. 263).

Muitos foram os congressos e grupos de debates que seguiram com essa mesma linha de questionamentos sobre as reformas curriculares no Brasil, até que nos anos 1990, após a aprovação da Lei de Diretrizes Bases da Educação Nacional - LDBEN (BRASIL, 1996), inicia-se uma discussão sobre propostas curriculares que atendessem a realidade do país, e surge nesse cenário os Parâmetros Curriculares Nacionais (BRASIL, 1997) como proposta de nortear o ensino na educação básica, não houve adesão total por parte das escolas, pois faltou no país políticas públicas de formação docente sobre as reformas curriculares, e a proposta apresentada de forma verticalizada seguiu por quase 20 anos sem ampla divulgação, mas passando também por revisões que passaram à margem nas escolas.

Após quase 20 anos, o Brasil novamente reúne vários professores, empresários, intelectuais e a "sociedade" para discutir um currículo de Base Nacional Comum Curricular - BNCC (BRASIL, 2017), em 2017, é publicada a 3. a versão do documento, e as escolas precisam de tempo e condições de trabalho para colocar em prática essa nova proposta curricular, nacional.

Com essas políticas públicas de reforma de currículo, de formação docente, de sistemas de avaliação, o professor tem tido oportunidade de falar? Os subalternos falam?

De fato, os desafios da formação docente têm se mantido em pauta nos congressos, seminários e conferências que discutem a qualidade da educação no Brasil, com isso, vimos que é fundamental estabelecer elos entre metodologias de ensino, teorias de aprendizagem, visando a necessária e oportuna possibilidade de o professor, falar.

\section{A proposta de formação subversiva responsável a partir da insubordinação criativa}

Nesse estudo não é objetivo desenvolver método de formação docente, mas mostrar como professores podem pensar sua própria prática a partir de metodologias e teorias que os instigue à insubordinação criativa, rompendo com modelos preestabelecidos e adaptando sua prática pedagógica a contextos e necessidades atuais. Ou seja, como assinala D'Ambrosio (2015) superar a acomodação do fazer pedagógico, e sair da sua gaiola profissional como ato de subversão responsável. (p. 8) 
As políticas públicas na área de educação têm formado um professor dentro de padrões estabelecidos pela demanda do mercado, no entanto esses modelos não têm atendido de modo satisfatório aos resultados das avaliações externas, como exemplo, PISA, em nível nacional - Brasil, e do SPAECE, em nível estadual - Ceará.

Face às demandas atuais, e entendendo que os modelos prescritos não têm dado conta de um profissional reflexivo, crítico, alguns formadores de professores têm buscado apresentar outros meios alternativos de formar professores de matemática para a Educação Básica, e nesse sentido, tem se apoiado nas metodologias e teorias que atendam a essas expectativas. Nesse estudo destacamos essas outras possibilidades metodológicas.

Nesse sentido, a formação docente que queremos tem em vista um profissional ético, crítico e reflexivo o qual ver o ensino como um ato pedagógico passível de transformação, pois como profissional tem consciência dos seus saberes e fazeres e sabe o momento de romper com alguns paradigmas para a tomada de decisão, no que se refere a necessária e responsável insubordinação criativa.

Os estudos sobre a TO e a SF como tendências na educação matemática ainda são preliminares, mas queremos com esse texto contribuir para ampliação dessa discussão visando apoio nos pressupostos da Insubordinação Criativa - IC, apresentada pelas professoras D'Ambrosio e Lopes (2015).

A proposta da insubordinação criativa pressupõe um profissional com capacidade de decisões, capaz de assumir sua prática e tomar atitudes, um sujeito que tem autonomia, mas que sobretudo tem consciência do seu papel de educador, e que tem clareza sobre a complexidade dos processos educacionais, e de acordo com D'Ambrosio e Lopes (2015, p. 9), sabem que as soluções para conflitos didáticos, pedagógicos e os impasses nas pesquisas somente ocorrem a partir de uma atitude de análise e deliberação dos profissionais autônomos. O que é autonomia docente? Para Freire(1996) a autonomia tem princípio educativo, bem como na relação entre autoridade e liberdade, e num movimento de equilíbrio e legitimidade, a autonomia faz sentido, e é nesse movimento dialético que se constrói e reconstrói a partir de sentidos coletivos e individuais com vistas às relações interpessoais desenvolvidas na convivência e respeito com o outro.

E pela autonomia responsável no fazer pedagógico, pela necessidade de rompimento das gaiolas epistemológicas, e rupturas com o fazer pedagógico prescrito, é importante que o professor tenha voz, questione, e use da subversão responsável.

\section{O currículo de matemática na Educação Básica: os subalternos podem falar?}

O currículo deve ser dinâmico e deve principalmente, atender à realidade do aluno, deve dar total autonomia ao professor, para que este não sufoque sua criatividade em meio a um currículo congelado e engessado que não atende às necessidades dos sujeitos e sem que resolva seus problemas. O currículo deve ser resultado de estudos sérios e profundos sobre a realidade local e deve possibilitar a professores e alunos serem sujeitos ativos e não passivos, como destaca Freire (1987, p. 9) o professor deve assumir-se como sujeito, frente ao processo educacional que envolve ensino e 
aprendizagem, currículo, e aos sistemas de avaliação, seja de sala de aula, seja avaliação em larga escala.

Como política pública educacional, no ano de 2017 no Brasil foi lançada a Base Nacional Comum Curricular - BNCC, que visa um currículo universal para realidades completamente diferentes. Antes disso, Freire (1987) já destacava a importância de se abandonar o tecnicismo e partir para um currículo multifacetado, que deveria estar em constante construção/reconstrução para atender às necessidades do sujeito.

Lopes (2012, p. 17), aponta que nos mais diferentes contextos nos quais as políticas curriculares se desenvolvem, dentre eles as escolas, há muitos rastros de enfoques instrumentais, às vezes inclusive com destaque, principalmente no que concerne à tendência prescrita. É nesse contexto que o professor deve "assumir atitudes de insubordinação criativa em prol daqueles que educam e do conhecimento que produzem e promovem." (D'AMBROSIO, LOPES, 2015, p. 10).

O currículo de Matemática deve visar à contextualização dos conteúdos com foco na realidade dos estudantes, promovendo uma aprendizagem de cunho significativo por meio de uma metodologia que vise à qualidade em detrimento da quantidade. Na compreensão de que currículo não é uma ação didática de fácil aceitação, isso pressupõe quebrar paradigmas, superar modelos ultrapassados, transpor barreiras hegemônicas, mas principalmente, é necessário que o professor se predisponha às mudanças, e isso gera desafios e questões de relação de poder, tanto de ordem pedagógica, mas principalmente, de ordem política.

No discurso sobre currículo, os subalternos falam?

O que se sabe é que a hegemonia pressupõe que se deve levar em conta os interesses e as tendências dos grupos sobre os quais ela deve ser exercida, e promover equilíbrio, conciliatório, ou seja, o grupo dominante deve fazer sacrifícios (APPLE \& BURAS, 2008, p. 12). É fato que existe uma necessidade premente dos grupos dominantes sobre os dominados - eles querem convertê-los. O conhecimento do dominador tem mais valor que o conhecimento do dominado? Tem mais valor 0 conhecimento de quem? Um saber se sobrepõe ao outro? Sobre isso Sagoyewatha, no livro de Apple e Buras (2008, p. 141-143) desabafa (...)vocês levaram vários de nossos jovens para suas escolas. Vocês os educaram e ensinaram sua religião. Quando retornaram à sua família e à sua cor, não eram homens brancos e nem índios.

A fala acima, feita a mais de dois séculos nos remete a pensar sobre a luta de grupos dominados contra a dominação, principalmente, sobre questões culturais e educacionais. Nas discussões sobre currículo, algumas vozes são cerceadas, e não ouvidas, especialmente, na implementação das políticas públicas curriculares.

Como as escolas reagem diante dessas políticas públicas? Qual conhecimento é validado na escola? As formações docentes seguem o conhecimento de quem?

$\mathrm{Na}$ escola, a equipe gestora e professores reúnem-se para conversar sobre políticas públicas curriculares e quais conteúdos devem ser ensinados, mas precisam pensar seus passos a partir do que aponta a BNCC (BRASIL, 2017), de certo, a atuação e interpretação dessas políticas passam pelas reflexões desses profissionais que nesse 
momento tem a escolha de seguirem engaiolados, ou exercerem a autonomia responsável, e manifestarem-se como subversivos com base nos pressupostos da insubordinação criativa, combatendo os discursos discriminatórios a esse tipo de ação.

Nesse sentido, professores e equipe gestora podem ser considerados subversivos, insubordinados, ou podem simplesmente com base no sentido do termo discricionário, agirem à luz da discricionariedade que é um termo relacionado a área do direito administrativo, mas que ainda há muita imprecisão, e, nesse texto, consideramos que:

"trata-se de uma faculdade de escolher uma entre várias significações contidas
num conceito normativo prático, relativo às condições-de-fato do agir
administrativo - escolha feita sempre dentro dos limites da lei. Esta escolha é feita
livremente pela Administração, entendendo-se aqui por liberdade aquilo que vimos
expor." Ou ainda, (...)“diante do caso concreto, tem a possibilidade de apreciá-lo
segundo critérios de oportunidade e conveniência e escolher uma dentre duas ou
mais soluções, todas válidas perante o direito." (DI PIETRO, 1991, p. 9-40)

Salvaguardado os efeitos legais dos atos discricionários administrativos, para a validade e eficácia de um ato administrativo, é necessária a adequação entre a medida adotada e os motivos que a motivaram, fundamentaram a atuação da Administração Pública, é nesse contexto que a equipe gestora e professores devem apresentar que no conteúdo do ato administrativo, há adequação lógica e proporção entre meios e fins. (FARJADO, 2015). Paralela à vinculação, que limita e cerceia a atividade de gestores das políticas públicas ao juízo de constatação da hipótese legal, existe a subversão responsável, consubstanciada na prerrogativa da insubordinação criativa do educador que escolhe eleger a melhor solução para a consecução da finalidade pública, e nos casos em que a lei lhe confere uma margem de liberdade, optam por falar, agir, tomar decisões, pautadas na ética, na ação-reflexão de forma consciente.

No entanto, não é tão simples, existe uma complexidade no debate educacional que é pautada pelas relações de poder. No século XXI, ainda se luta por conhecimento e voz, mas a força dos subalternos ainda é tolhida. Quem são os subalternos na disputa pelo currículo? Historicamente, os subalternos, em 1700, eram os vassalos e camponeses, pessoas das classes mais baixa do exército. No início do século XX, Gamsci ${ }^{1}$ usava esse termo (como código) para indicar grupos oprimidos, como operários industriais, e camponeses, e em seus Cadernos, ao circularem nas décadas de 1960 e 1970, apresentam mais claramente o conceito de Gramsci sobre o subalterno, seja nos estudos culturais, ou em teorias e pesquisas críticas educacionais.

As disputas educacionais entre grupos dominantes e subalternos para definir o que conta como conhecimento e para apropriação de recursos políticos, econômicos, culturais e sociais em uma variedade de contextos educacionais, (em âmbito nacional e local), são reflexos de uma luta de poder que envolve a disputa sobre o currículo comum, currículo oficial, currículo cultural (subalterno). Assim, mesmo com as limitações das ações subalternas - conhecimento e voz - são objetos de luta dos educadores crítico-reflexivos contra relações de dominação e subordinação, e ao falarmos nos subalternos insurge uma discussão sobre diversos grupos submetidos a relações de poder desiguais.

Sobre essas relações de poder desigual, Apple \& Buras (2008, p. 14) advertem que

\footnotetext{
1 Ativista político encarcerado na Itália fascista no final da década de 1920, usou essa palavra em seus cadernos de cárcere. (APPLE \& BURAS, 2008, p. 12)
} 
seja em salas de aula, seja em salas de reunião, nas universidades ou fundações -, cada espaço se caracteriza pela dinâmica do poder diferencial e pelas complexidades e contradições da identidade e da ação. Nas áreas do currículo, da política educacional e da reforma, lutas de todos os tipos ocorrem nos circuitos de produção, distribuição e recepção.

\section{A SF e a TO conexões práticas com a IC: falam os subalternos}

Existe uma luta de superação de um currículo conteudista que inviabiliza mudanças significativas na qualidade de ensino na escola. Com isso, vimos que é necessário um currículo com bases multiculturais e interdisciplinares, para a transformação social, apresentando a escola, como o espaço em que se aprende a aprender, a conviver e a ser com e para os outros, contrariando um tipo de currículo que segrega. Nesse contexto, na escola, o currículo torna-se terra fértil para mudanças ou simplesmente para manter o status quo, a depender das relações microfísicas de poder.

A (re)construção de um currículo que vise colaborar para constituição de novos paradigmas nos processos de ensino e de aprendizagem que direcione a instituição escolar a se sobressair frente a um modelo de ensino conteudista. Esse enfrentamento exige mudança de postura de docentes e gestores, para que juntos possam inovar nas práticas pedagógicas, escolher, com qualidade, suas metodologias, e novas formas de avaliação, tendo como um documento de referência - o currículo, mas um currículo dinâmico e multifacetado.

Inferimos que a política que envolve produção, distribuição e recepção do conhecimento curricular é intensa e complexa, e que as disputas pelo currículo - sobre quais experiências serão representadas como válidas ou qual língua ou história será ensinada - são constantes. Tais conflitos são presentes, à medida que multiculturalistas de todas as linhas protestam por maior heterogeneidade no currículo. As lutas pela hegemonia curricular concentram-se na produção e na distribuição do conhecimento, e nas escolas se presencia um foco crescente em como as próprias funcionam como locais de recontextualização do corpus formal do conhecimento.

É fato que o conhecimento nunca é transmitido de forma fácil, seja: (a) do currículo para o professor; (b) do livro didático para o aluno; ou mesmo, (c) do professor para o aluno. Para Apple \& Buras (2008, p. 31) (...) o currículo oficial sempre é reconstruído no nível da recepção, à medida que professores e alunos entram no interminável processo cotidiano de compreensão, resistência, ensino e aprendizado. (...) nenhum dos conflitos (...) ocorre em um solo nivelado.

Apple \& Buras (2008) apresentam uma reflexão que se passa na Inglaterra, mas de forma globalizada, e, portanto, nos apoiamos nessas reflexões porque aqui no Brasil essa discussão acontece de forma bem semelhante, como exemplo, haja vista as políticas públicas de currículo, em 1997, com os Parâmetros Curriculares Nacionais - PCN e, em 2015-2016, a Base Nacional Comum Curricular - BNCC (BRASIL, 2017), que é lançada em 2017, refletindo a limitação da voz do professor nessa construção. E nisso, Freire (1987, p. 19) nos conduz a refletir que sem o diálogo com os oprimidos, não é possível práxis autêntica, nem para estes nem para ela. O autor continua (...) para dominar, o 
dominador não tem outro caminho senão negar às massas populares a práxis verdadeira. Negar-lhes o direito de dizer sua palavra, de pensar certo.

Com isso, queremos entender melhor a dinâmica das relações de poder, as apostas e as possibilidades democráticas na elaboração do currículo no Brasil. Apple (2001, p. 218) destaca uma visita feita ao Brasil: Durante umas das vezes em que estive no Brasil trabalhando com Paulo Freire, lembro-me de ele me dizer repetidas vezes que a educação deve começar no diálogo crítico. E nisso, o autor reforça que conhecer a realidade de outros países é relevante para estimular uma reflexão crítica que cruze fronteiras, mas que valorizar sua própria realidade é mais produtivo.

As reflexões sobre a práxis envolvem de um lado a autonomia - com manifestações de insubordinação criativa sobre o currículo, e de outro lado os quefazeres dos opressores - a partir da ação antidialógica que submerge a subversão responsável, que calam os professores e gestores. Mas Freire (1987) diz saber que é preciso respeitar à autonomia e à identidade do educando exige de mim uma prática em tudo coerente com este saber.

Freire (1996) destaca que a formação deve estar a serviço da libertação permanente, e da humanização do ser. Assim, tanto a SF como a TO são metodologias e teorias de formação docente preocupadas com os quefazeres na/para a escola básica, considerando nesse caminhar que professores e pesquisadores precisam mobilizar não só teorias e metodologias, mas também suas concepções, seus sentimentos e seu saberfazer. (D'Ambrosio e Lopes, 2015).

\section{Considerações}

As discussões que o texto apresenta envolvem temáticas importantes que influenciam a formação docente de sobremaneira, sendo elas importante para reformar 0 complexo espaço escolar. Sobre isso, Gramsci nos lembra que antes, a escola era só mais um sistema de hegemonia ideológica onde os indivíduos eram direcionados a manter o status quo. No entanto, as reflexões nos conduziram a pensar que para se alcançar algum sucesso com a participação ativa dos alunos, a escola deveria estar relacionada à realidade. Os alunos devem ser ativos e para isso é preciso superar a ideia de educação bancária a qual Freire $(1987,33)$ condena, pois "Em lugar de comunicar-se, o educador faz "comunicados" e depósitos que os educandos, meras incidências, recebem pacientemente, memorizam e repetem."

Concordamos que o ensino deve ser libertador, instigador de criatividade, a partir da realidade da vida dos sujeitos, Gramsci defende uma escola não técnica, que interessa não apenas ao indivíduo, mas à coletividade. Nessa escola, as classes desfavorecidas podem se inteirar dos códigos dominantes, inclusive dos de alfabetização. A construção de uma visão de mundo que desse acesso à condição de cidadão teria a finalidade inicial de substituir o que Gramsci chama de senso comum - conceitos desagregados, vindos de fora e impregnados de equívocos decorrentes da religião e do folclore.

Sobre as políticas públicas de formação docente para Ball (2014), há novas vozes nas conversas sobre políticas e novos canais por meio dos quais os discursos sobre 
política (na escola), são introduzidos (...) (p. 34), e nesse sentido, tanto a SF como a TO, mostram que é importante que o professor fale, discuta política com a finalidade de formação de um aluno crítico, fortalecido logo nos primeiros anos escolares por um currículo que the apresente possibilidades de lutas pela cidadania.

Mas como ser um professor subversivo responsável a partir da insubordinação criativa? As reflexões ora postas, nos remetem ao comportamento insubordinado criativo subversivo responsável do professor CONRACK, no filme - um educador por excelência, que rompeu com regras, não se subordinou ao sistema, pois pensava numa educação alegre, crítica, que rompesse as barreiras da desigualdade de raça, classe, relações de poder e a cor da pele. (RAVETCH; FRANK, 1973)

Não queremos classificá-lo como um herói da educação, mas ressaltamos sua postura diante do sistema escolar que Ihe foi imposto. Infelizmente foi um lutador solitário, e isso o enfraqueceu diante do poder do sistema escolar frente ao cenário de segregação das crianças negras, naquela época. No entanto, se CONRACK, tivesse melhor planejamento, conhecimento de metodologias, e melhor organização didática, poderia ter alcançado melhores resultados. Mas, inferimos que Conrack desafiando leis e mandatários, consegue plantar a semente de luta naquelas crianças, e isso só se dá pela sua insubordinação criativa.

Um professor com essa postura precisa ter passado por uma formação pautada na criticidade, na ética e na humanização, que lhe proporcione, manifestações de insubordinação criativa, e the desperte a consciência que sair da gaiola profissional é um ato de subversão responsável.(D'Ambrosio e Lopes, 2015, p. 8). Por fim, a ideia é de não separar essas dimensões (criticidade, ética e humanização), pois integradas, nos permitem aperfeiçoar a qualidade de ações e relações, e auxiliam a superar a visão de poder e autoridade vinculada ao cumprimento rigoroso das regras, que envolvem a luta do novo contra o conservadorismo - luta da insubordinação criativa $x$ prática reprodutivista.

\section{Referências}

ANAIS. CONGRESSO NACIONAL DE ENSINO DA MATEMÁTICA NO CURSO SECUNDÁRIO, I, 1955, Salvador: Universidade da Bahia, 1955.

APPLE, M. et al. Currículo, poder e lutas educacionais: com a palavra, os subalternos. Tradução de Ronaldo Catado Costa. Porto Alegre: Artmed, 2008.

BALL, S. J. Educação global S.A.: Novas redes políticas e o imaginário neoliberal. Ponta Grossa: UEPG, 2014. (Tradução: Janete Bridon)

BRASIL. Ministério da Educação. Portaria MEC n.. 790, de 27 de julho de 2016. Institui o Comitê Gestor da Base Nacional Curricular Comum e reforma do Ensino Médio. Diário Oficial da União, Brasília, 28 de julho de 2016, Seção 1, p. 16. Disponível em: http://portal.mec.gov.br/index.php?option=com_docman\&view=download\&alias=46471link-port-790-base-curricular-pdf\&category_slug=julho-2016-pdf\&ltemid=30192. Acesso em 23 de março de 2017. 
Lei de Diretrizes e Bases da Educação Nacional(LDBEN), n.. 9394/96. Lei n..ำ 12.796, de 2013.

Parâmetros curriculares nacionais(PCN). Secretaria de Educação Fundamental. - Brasília: MEC/SEF, 1997.

D'AMBROSIO, B. S; L, C. E. Insubordinação Criativa: um convite à reinvenção do educador matemático. Bolema, Rio Claro (SP), v. 29, n. 51, p. 117, abril de 2015.

DIAS, A. M. I; MAGALHÃES, E. B; FERREIRA, G. N. L.(Org.). A aprendizagem como razão do ensino: por uma diversidade de sentidos. 1ed.Fortaleza: Imprece, 2016, v. 1.

DI PIETRO, M. S. Z. Direito Administrativo. 10ª ed. São Paulo: Atlas, 1999.

DI PIETRO, M. S. Z. Discricionariedade Administrativa na Constituição de 1988. São Paulo: Atlas, 1991.

FAJARDO, M. C. V. Controle dos Atos Administrativos Discricionários. In: Âmbito Jurídico, Rio Grande, XVIII, n. 135, abril 2015. Disponível em: http://www.ambitojuridico.com.br/site/?n_link=revista_artigos_leitura\&artigo_id=15926. Acesso em agosto de 2017.

FREIRE, P. Pedagogia da autonomia: saberes necessários à prática educativa. São Paulo: Paz e Terra, 1996. - (Coleção Leitura)

FREIRE, P. Pedagogia do oprimido, 17. a edições, Rio de Janeiro, Paz e Terra,1987.

GUTIÉRREZ. R. Why (Urban) Mathematics Teachers Need Political Knowledge. In: Journal of Urban Mathematics Education, 2013, Vol. 6, No. 2, pp. 7-19.

MARX, K. Manuscritos econômico-filosóficos. São Paulo: Boitempo, 2004.

RADFORD, L. Methodological Aspects of the Theory of Objectification. Perspectivas da Educação Matemática, 2015. v. 8(18), 547-567.

RADFORD, L. Cultura e história: dos conceptos dificiles y controversiales en aproximaciones contemporaneas en la educación matemática. In: MENDES, Iran; FARIAS, Carlos Aldemir (Orgs.). Práticas socioculturais e educação matemática. São Paulo: Livraria da Física, 2014. p. 49-68.

RADFORD, L. Elementos de uma teoria cultural de la objetivación. Relime. número especial. 2006. pp.103-129.

RAVETCH, I.; FRANK Jr, H. Conrack (Roteiro). Revisão Final de 5 de março de 1973. USA.

SANTOS, M. J. C. dos. Reaprender frações por meio de oficinas pedagógicas: desafio para a formação inicial. (Dissertação e Mestrado). Fortaleza: UFC, 2007.

SOARES, F. Movimento da Matemática Moderna no Brasil: Avanço ou Retrocesso? Rio de Janeiro, Pontifícia Universidade Católica. Dissertação de Mestrado em Matemática, 2001.

SOUSA, F. E. E. et al. (Orgs.). Sequência Fedathi: uma proposta pedagógica para o ensino de Ciências e Matemática. Fortaleza: Edições UFC, 2013. 
SPIVAK, G. C. Pode o subalterno falar?. Belo Horizonte: Editora UFMG, 133p., 2010 [1985]. Tradução do original em inglês: Sandra Regina Goulart Almeida, Marcos Pereira Feitosa e André Pereira Feitosa.

VYGOTSKY, L. S. A construção do pensamento e linguagem. São Paulo: Martins Fontes, 2001.

\title{
APÊNDICE 1
}

\section{Proposta da Sessão Didática}

Sessão Didática: números e operações

As primeiras ações apontadas tem como pressupostos as premissas da Sequência Fedathi-SF. Nesta sessão didática inicialmente, realizamos a análise ambiental; a construção do plateau; a análise teórica; e, a escolha da pergunta inicial com a finalidade de nortear a oficina. (SOUSA et all, 2013).

Também nos apoiamos nas concepções de atividade da Teoria Cultural da Objetiva-TO. (RADFORD, 2014, p. 21).

\begin{abstract}
La actividad que ocurre en el aula de matemáticas tiene un objeto. Dicho objeto es identificado, a priori, por el proyecto didáctico del profesor. Este objeto puede ser, por ejemplo, el encuentro de los estudiantes con formas culturalmente codificadas de pensar algebraicamente sobre secuencias. Puede ser también el encuentro con formas culturalmente codificadas de pensar matemáticamente sobre el movimiento, sobre las fracciones, etc. En todos los casos, mientras el saber es pura posibilidad, la actividad que lo media es un paso hacia la concreción de ese saber. La actividad (que es sistema en movimiento) se mueve hacia su objeto. Para que la actividad se despliegue en la dirección de su objeto, conviene identificar una o más metas. Estas metas pueden ser, si continuamos con nuestro ejemplo de álgebra, resolver problemas sobre secuencias de manera algebraica. Para alcanzar las metas de la actividad, conviene que se conciban tareas específicas. Éstas pueden aparecer como una secuencia de problemas relacionados de dificultad conceptual creciente. En el caso de la teoría de la objetivación, esta componente implica un análisis epistemológico del contenido matemático que complementamos con un análisis a priori (Artigue, 1995, 2009).
\end{abstract}

Por ser uma turma em que o primeiro contato entre alunos e o professor já se dará na aplicabilidade desta sessão didática, torna se por necessário que tomemos algo como referência para assim partirmos de um conjunto de conhecimentos em comum. Contudo, não é nossa intenção abordar questões excessivamente básicas a partir do núcleo comum de conhecimentos já adquiridos pelos cursistas, mas que partindo de conceitos compreendidos, possamos, assim, adentrar em espaços mais reflexivos e complexos a partir da exposição dos problemas.

Quanto ao conteúdo, a ser abordado, diz respeito a temática números e operações, com ênfase nos conteúdos de 1.ำ ao 5.ำ ano do Ensino Fundamental dos Anos Iniciais, em que os cursistas, seja na sua formação inicial ou contínua, já possuam uma bagagem cognitiva que sustente as estruturações intelectíveis que pretendemos provocar.

\section{Análises gerais}

A importante contribuição do reconhecimento dos saberes iniciais dos alunos, público alvo e lócus de realização da sessão didática.

\subsection{Público alvo}

Graduandos do curso de Pedagogia da Universidade Federal do Ceará - UFC e professores da Rede Pública do Ensino Fundamental dos Anos Iniciais. 


\subsection{Experiências prévias da turma - plateau}

Devido o público alvo ser formado por alunos do curso de Pedagogia e professores (as) da rede pública, suas experiências pessoais e escolares adquiridas no dia a dia ou nas práticas de formação continuada de professores fornecerá importantes contribuições ao que se pretende discutir nesta sessão didática.

Desta forma, a sistematização estas informações já adquiridas pelos alunos proporcionará ao professor a construção de um patamar comum de conhecimentos entre os cursistas, ou seja, o desenvolvimento do plateau. Com vistas a compreender essas informações, um questionário foi elaborado como forma do professor obter e compreender estes conhecimentos mínimos já construídos e, consequentemente, servir como base as suas mediações as etapas seguintes.

\section{Conteúdo da Sessão Didática}

Números e Operações - Interpretação e resolução de situação-problema para as turmas do 1.ำ ao 5.ำ ano do Ensino Fundamental da Educação Básica.

\subsection{Levantamento bibliográfico sobre o assunto}

A compreensão de determinados conceitos matemáticos implica não necessariamente na memorização de estratégias visando apenas o resultado ou resposta final de um problema, mas um rico processo por vezes cíclico de contextualizações e abstrações tendo por consequências a capacidade de questionar, imaginar, visualizar, decidir, representar e criar (BRASIL, 2015).

Para que isto ocorra, o ensino de matemática deve proporcionar ao aluno observações sistemáticas no seu contexto de modo que como produto, variadas inter-relações entre outras áreas do conhecimento sejam feitas e assim desenvolvidas novas formas de raciocínio e processos. Em particular, estas ações serão desencadeadas na interpretação e resolução de problemas matemáticos sem relacionálos a práticas já internalizadas mecanicamente, mas compreendidas em seu arranjo processual.

Assim, na sistemática que trata do conhecimento dos Números e Operações, as principais atitudes a que se espera do aluno, está em que adquira 'autonomia no pensamento numérico sem as amarras de convenções e formalizações desnecessárias' (BRASIL, 2015, p. 252). A reflexão sobre as estratégias já compreendidas pelos alunos reforçam a reestruturação destes esquemas a outros mais elaborados e, principalmente, carregados de significância para o aluno.

\subsection{Saber científico do conteúdo abordado}

Antes de compreender como se dá a atuação das operações ou algoritmos em diferentes contextos, os alunos necessitam construir a ideia de número como condição fundamental ao tratamento de matemáticas mais complexas. A ideia de número foi construída e aperfeiçoada ao longo de muitos anos, pois surgiu da necessidade do homem em conhecer o mundo e nele sobreviver. Assim, foi desta necessidade e utilizando objetos para a contagem que a humanidade começou a construir o conceito de número. (NOGUEIRA, 2011).

Construído o conceito de número, um espaço maior de reflexões se darão no campo das discussões sobre as operações ou relações entre os números, de modo que estas operações se darão num movimento em 'espiral' recorrente já nos primeiros anos SANTOS (2010). Ou seja, há um avanço no momento que estruturas já se encontram estabilizadas e estas passam a servir como referência a elaboração de outras, bem como é perfeitamente possível e as vezes necessário o retorno a ideias anteriores quando da necessidade do aluno em compreender com maior exatidão o que de novo compreenderá.

Partindo de um contexto mais amplo, para Vergnaud (2001) as operações partem do entendimento sobre ações de pensamento que não se deixam reduzir a operações numéricas, mas implicam também raciocínios sobre quantidades e grandezas. Ao construírem estas estruturas, o sujeito diante de variadas situações, organiza determinados comportamentos que de forma invariante tenta responder a estas situações, a que o autor chama de esquemas.

Santos (2010) não se opondo, mas complementando Vergnaud (2001) se volta ao entendimento das operações sendo a ação voltada sobre os objetos visando suas transformações, num 
processo de interação com as operações físicas que construímos durante o desenvolvimento das operações de pensamento.

\subsection{As dificuldades relacionadas ao ensino dos números e operações quanto a interpretação e solução de problemas}

Com a exposição de um problema matemático ao aluno, é perfeitamente possível que de imediato uma de suas primeiras indagações ao professor seja saber qual o tipo de operação que deve ser realizada para resolvê-lo. Surge nesse contexto, questionamento, 'é de mais', 'menos', 'multiplicar' ou 'dividir'. Na linha desse raciocínio, há um déficit por parte do aluno em tratar como verdade incondicional o fato que para todo problema matemático há uma 'fórmula' ou estratégias para resolvê-lo e que sua função é encontrar este conjunto de regras de forma mais rápida possível.

Com isto, a compreensão de uma questão matemática pelos alunos, por antecipação, torna-se ineficiente, pois o estudante ao procurar de imediato 'modelos' ou estratégias já determinadas para sua solução não permite que as operações atuem como instrumentos para a resposta e não o fim em si mesmas. Como bem coloca Ferreira $(2012$, p.3) o processo 'fica reduzido a uma atividade mecânica de repetição de respostas e estruturas que, muitas vezes, encontram-se vazias de significação'.

Como consequência, o aluno se submete a permanecer 'treinado' a resolver problemas apenas por saber utilizar alguns algoritmos permanecendo, assim, sem o poder de inferência diante das questões colocadas. Um outro elemento que agrega enorme importância a compreensão e solução de problemas matemáticos, está no uso do cálculo mental como ferramenta para a escolha de melhores estratégias, pois,

Saber calcular mentalmente é uma capacidade que se deveria considerar básica, não só ao nível das aprendizagens escolares mas também ao nível da vida quotidiana. É preciso repensar a importância do cálculo mental na vida de todos nós e perceber qual o papel da escola e dos professores no desenvolvimento desta capacidade (CARVALHO, 2011, p.7).

Seja na manifestação do cálculo mental em situações do cotidiano ou na interação com problemas matemáticos formais que precisem da abstração de operações, estes aspectos nem sempre caminham em sintonia no processo de aprendizagem, como bem, coloca Carvalho (2011) os alunos manifestaram dificuldades em mobilizar estratégias utilizadas com frequência no cálculo mental em contextos matemáticos, razão esta que corrobora com a ideia de dissociação entre operações mentais e envolvendo logaritmos.

\subsection{O Ensino dos números e operações na atualidade}

Há um vasto conjunto de trabalhos que expõem e promovem infindáveis discussões sobre metodologias que melhorem as práticas do professor no que tange a compreensão e tratamento das operações no ensino fundamental. Como destaca Santos (2013, p. 109) Novas metodologias inovam o ensino para se obter uma melhor aprendizagem; visões diferenciadas de avaliações internas e externas adentram as escolas e os sistemas escolares; propostas curriculares tentam adequar o conhecimento escolar à realidade social na qual vivemos.

É compreensível que em se tratando do ensino nas séries iniciais do Ensino Fundamental da Educação Básica a construção do saber parta de questões concretas e vivenciáveis pelos alunos de modo que para alcançar a abstração é preciso começar pelo concreto, este é o caminho para a formação de conceitos de uma forma mais significativa ao aluno (LORENZATO, 2010).

Contudo, tal prática não se sustenta e nem progride apenas na sua compreensão concreta, o sujeito precisa elaborar hipóteses e intuitivamente ultrapassar o campo do raciocínio matemático concreto com vistas a adquirir algo mais avançado, como o raciocínio aritmético e algébrico. A questão é que diante da construção destes raciocínios mais aprimorados, muitos são os esquemas colocados pelos docentes que usualmente acabam memorizados sem qualquer significância para o aluno, tendo como único intuito reduzir ou facilitar os caminhos para uma rápida resolução do problema (VERGNAUD, 1993).

\subsection{Pré requisitos necessários para a compreensão do conteúdo}

Para compreensão do conteúdo, é necessário que os cursistas tenham conhecimento do conceito de número, sistema de numeração decimal e as operações básicas (adição, subtração, multiplicação e divisão). 


\section{0 ambiente}

A oficina ocorrerá na Faculdade de Educação da Universidade Federal do Ceará - UFC. O ambiente escolhido é o mais indicado para a realização desta ação porque atende quanto aos espaços e estrutura. Adequado para os trabalhos que ocorrerão, a possibilidade de concentrar uma considerável quantidade de cursistas permitirá que vários grupos sejam constituídos permitindo, assim, que diferentes discussões ocorram.

\subsection{Material}

Ter consciência de que os materiais escolhidos para a realização dessa ação pedagógica estão acessíveis e disponíveis no lócus, ou se será necessário acionar outras variáveis.

\subsubsection{Materiais}

Material analógico: papel ofício A4, pincéis e fita adesiva.

Material digital: notebook e data show.

\subsubsection{Duração da aula}

Dois momentos de 50 minutos intercalados por um intervalo de 15 a 20 minutos.

\subsection{0 potencial dos recursos e as possibilidades}

Com a exposição oral sobre as ações que constituem o início dos trabalhos (contrato didático e tomada de posição), o uso de práticas envolvendo trabalhos em grupos e a apresentação de slides promoverão discussões e reflexões interessantes e necessárias a conquista do objetivo desta sessão didática.

\section{Variáveis locais - hipóteses levantadas}

As variáveis e as hipóteses apresentadas baseiam-se na corrente filosófica dialética sobre a qual tratamos compreender o tripé: professor-conteúdo-aluno. Preocupadas com a influência simplificadora do senso comum, objetivamos mostrar a importância da noção de dialética utilizada na elaboração desta sessão didática - tratamos aqui, portanto, de um sistema de compreensão da realidade, em que elementos tomados como dialéticos, envolvessem não só a ideia sobre as coisas, mas a realidade em que elas estão inseridas.

\subsection{Do Conteúdo}

Para cada tipo de questão sua solução possui uma estratégia diferente.

A interpretação do problema é mais bem compreendida diante da solução já encontrada.

\subsection{Do aluno}

Para resolver um problema basta saber algum termo que indique qual operação utilizar.

Há estratégias mais eficientes que outras.

Uma estratégia poderá resolver vários tipos de problemas.

Um problema pode ser resolvido por várias estratégias distintas.

\subsection{Do professor}

Os alunos compreendem apenas uma forma de resolução da questão colocada.

Diante de um problema o aluno tende a querer encontrar uma palavra que oriente que tipo de operação deve ser feita. 


\section{Objetivo}

professor

Objetivos a serem alcançados com a sessão didática a partir das ações pedagógicas mediadas pelo

\subsection{Geral}

Compreender os conteúdos matemáticos envolvendo Números e Operações no que diz respeito a construção de estratégias na resolução de problemas matemáticos referentes ao 1‥ ao 5․ ano do Ensino Fundamental por meio de uma sessão didática.

\subsection{Específicos}

As ações aqui detalhadas permitirão que os cursistas, de modo específico, possam:

- [Re]construir suas hipóteses sobre a resolução de problemas matemáticos perante a relação entre interpretação de problemas e operacionalização dos algoritmos.

- Planejar de modo mais efetivo, as estratégias na abordagem de questões matemáticas para

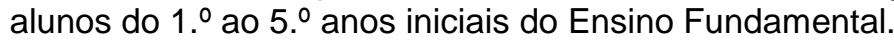

- Contribuir de forma significativa com o ensino dos alunos do 1. ao 5. anos iniciais do Ensino Fundamental, no que se refere ao conteúdo Número e Operações.

\section{Acordo didático}

Com o propósito de suscitar provocações e reflexões nos cursistas sobre suas formas de interpretação e resolução de problemas, como diálogos iniciais para a elaboração do contrato didático, é de nosso entendimento que fique claro a postura que caberá ao professor, pois sua atuação se dará principalmente na mediação diante das questões levantadas, provocando os questionamentos e sistematizando as soluções encontradas.

Ao aluno caberá o caráter investigativo diante das questões colocadas, assumindo, embora que implicitamente, seu papel como protagonista do próprio processo didático (CHEVALLARD et al 2001).

\section{A sessão didática}

Perguntas como estratégia mediadora da aprendizagem dos alunos, e subsídios teóricos e metodológicos do professor em ação.

7.1 A pergunta principal - Trataremos agora de apresentar algumas questões matemáticas a vocês e ao analisá-las, eu gostaria que dissessem o que entenderam e como as resolveriam.

7.2 Perguntas reflexivas - É possível que para estas questões existam novas formas de resolução? Caso existam, algumas são melhores ou mais eficientes que outras?

7.3 Perguntas desafiadoras - Diante destes problemas com suas respectivas soluções eu gostaria que discutissem em grupo quais as possíveis outras formas de resolução e caso existam, as apresentasse no grande grupo.

\section{Tomada de posição}

Primeira etapa da ação metodológica em sala de aula.

\subsection{Apresentação do acordo didático}

Esperamos que tentem expressar o pensamento de vocês, suas hipóteses e ideias sobre o que estou Ihes propondo. Toda opinião é valida e reconheçam no erro, caso ocorra, a oportunidade de trilhar por outras estratégias ou caminhos. Trabalhamos as dúvidas que possam surgir, mas o cursista é o principal ator para elucidar as questões, independentes que a resposta/solução esteja correta ou não. 


\subsection{Situação desafiadora}

Apresentação do probelma principal para os cursistas responderem, sob a orientação do formador. Pode ser trabalhado com duplas da maneira que considerar mais adequado.

Solicitar aos cursistas que elaborem uma situação-problema, envolvendo as quatro operações fundamentais: adição, subtração, multiplicação e divisão, em que devem ser observados nessa stiuaçãoproblema, a fim de preencherem a tabela que contém os itens:

\section{Saber do aluno:}

a) Conhecimento prévios para a solução do problema;

b) Faixa etária para a resolução;

c) Possíveis estratégias de solução.

\section{Saber do professor:}
a) Dificuldades encontradas na elaboração da situação-problema;
b) Metodologia usada;
c) Escolha de material e forma de avaliação do saber do aluno.

\subsection{As hipóteses}

- Existe apenas esta solução para este problema?

- Caso exista outras formas de resolução, o que se diferencia entre elas?

- Seria algumas mais abrangentes que permitissem a solução de outras questões ?

- Há alguma palavra ou expressão que indique que tipo de operação deve ser feita?

\section{Maturação}

I - Cada dupla tera um tempo para discutir e refletir sobre a possibilidade de existir outra forma de expor a resposta, passado este intervalo de tempo, a equipe seguinte receberá a mesma situação. $O$ processo chegará ao fim quando a mesma questão findar no grupo que a respondeu inicialmente.

II - Para cada grupo em que as questões forem analisadas, os membros terão que descrever como chegaram a solução, ou seja, detalhar qual estratégia foi utilizada. Com o término desta ação, estas soluções serão encaminhadas aos outros grupos para que assim as analise e reflita sobre a possibilidade de novas fomas de resolução.

III - Os espaços de reflexão girarão em torno de possíveis outras hipóteses ou estratégias de resolução. O professor irá acompanhar estas ações mediando as discussões dentro do proprio grupo, na medida que os debates ocorrerem, novos contraexemplos serão expostos de modo que permita a solução e conclusão dos problemas colocados inicialmente.

\subsection{Contraexemplos}

Mesmo que tais respostas sejam respondidas no momento das apresentações, o professor como forma de suscitar os debates e melhorar as considerações levantadas, há de expor que;

- Caso permaneça este mesmo contexto da pergunta mudando se apenas os valores, esta estratégia por vocês utilizada ainda será a melhor?

- Haveria alguma estratégia que mesmo mudando as quantidades num mesmo contexto sua utilização seria mesma?

- Podemos considerar que existam estratégias melhores que outras? 


\section{Solução}

Quando a questão inicial já tiver percorrido todos os grupos, cada dupla deverá elaborar uma síntese mostrando que conclusão chegaram diante das respostas realizadas pelos outros grupos. Este resumo e suas conclusões será exposto na plataforma virtual para que os demais opinem e, assim, novas e melhoradas produções sejam feitas e compartilhadas como produto final pelo professor mediador.

\subsection{Contraexemplos da Solução}

Expostos todos os grupos com suas respectivas conclusões, o professor questionará; - haveria então mais alguma questão a ser acrescentada sobre o que foi 'achado' por vocês na análise destas questões? - De posse do cohecimento sobre diferentes estratégias para o mesmo problema, quais os impactos que tais ideias podem interferir no ensino do 1.0 ao $5 .^{\circ}$ ano do ensino fundamental? oficina.

Essas ações servirão de norte para a elaboração e resolução da situação problema proposta na

\section{Prova}

O professor irá expor um breve resumo sobre alguns trabalhos voltados a análise de diferentes raciocínios ou estratégias matemáticas usadas na resolução de problemas, com isto, os alunos terão um aporte teórico para concluirem suas hipóteses sobre o que trabalhamos até agora.

Após as análises das situações propostas pelos cursistas, o coordenador da oficina, solicitará uma apresentação de no máximo 5 minutos sobre os quatro tipos de racicínio matemáticos apontados inicialmente por Johannot (1947) e aprofundados por Barreto (2001). Para isso é relevante a leitura com antecedência do texto.

Como finalização, o professor de posse das colocações feitas pelos alunos em referência os estudos sobre os diferentes racicínios, sistematizará o que até aquele momento foi discutido captando-os a partir do que foi produzido pelos alunos à luz das considerações teóricas de Johannot, e cada grupo fica responsável em postar no protfólio de grupo a síntese da discussão em sala de aula, que fomentará também o fórum de discussão no TelEduc/multimeios.

\section{Avaliação}

A partir das percepções colhidas inicialmente perante os problemas colocados, trataremos de sistematizar estas novas hipóteses, de modo que os cursistas reflitam sobre a importância do aluno ao interpretar e inferir sobre diferentes estratégias na solução de problemas.

A conclusão destas novas percepções pelos cursistas se dará não somente no final deste processo, como em ambiente virtual que atuará como extensão a este processo. A conclusão dos trabalhos referente ao momento presencial se dará na sistematização das ideias discutidas nos grupos e novamente encaminhadas para a opinião dos demais em ambiente virtual, o qual será por meio do fórum.

\section{Considerações}

Essa temática é complexa e instigadora, nesse sentido, um maior aprofundamento quanto a parte teórica destes conteúdos será realizado por meio virtual. É condição para a conclusão da carga horária desta e das demais oficinas a participação numa plataforma virtual em que outros aspectos serão abordados e discutidos.

\section{Algumas referências}

BARRETO, Marcília Chagas. O Desenvolvimento do Raciocínio Matemático. Tese de Doutorado. Universidade Federal do Ceará, 2001.

BORGES NETO, H. e DIAS, A. M. I. Desenvolvimento do raciocínio lógico matemático no 1.ำ grau e na préescola. Cadernos de Pós-Graduação em Educação: Inteligência - enfoques construtivistas para o ensino da leitura e da matemática. v. 2 Fortaleza, CE: Imprensa Universitária/UFC, 1999. 
BRASIL. Ministério da Educação. Base Nacional Comum Curricular. Brasília, DF: MEC, 2015. Disponível em: http://basenacionalcomum.mec.gov.br/documentos/bncc-2versao.revista.pdf. Acesso em: 27 ago. 2016.

CHEVALLARD, Yves; BOSCH, Marianna; GASPÓN, Josep. Estudar matemáticas: o elo perdido entre o ensino e a aprendizagem. Porto Alegre: ArtMed Editora, 2001.

FREIRE, P. Pedagogia da autonomia: saberes necessários à prática educativa. 31. ed. Rio de Janeiro: Paz e Terra, 2005.

NOGUEIRA, Clélia Maria Ignatius. Pesquisas atuais sobre a construção do conceito de número: para além de Piaget?. Educar em Revista, 2011.

SANTOS, Joelma Nogueira dos. A construção do conceito de número natural e o uso das operações fundamentais nas séries iniciais do ensino fundamental: uma análise conceitual. 2013. $180 \mathrm{f}$. Dissertação (Mestrado em Ensino de Ciências e Matemática) - Centro de Ciências. Universidade Federal do Ceará, Fortaleza, 2013.

SOUSA, F. E. E. de. et al. (2013). Sequência Fedathi: uma proposta pedagógica para o ensino de Matemática e ciência. Fortaleza: UFC, 2013.

VERGNAUD, G. Teoria dos campos conceituais. In NASSER, L. (Ed.) Anais do 1ํ Seminário Internacional de Educação Matemática do Rio de Janeiro. p. 1-26. 1993.

. O longo e o curto prazo na aprendizagem da matemática. Educar em Revista, Curitiba, Brasil, n. Especial $1 / 2011$, p. 15-27, 2011. Editora UFPR.

VIGOTSKI, Lev Semionovich. A formação social da mente. 6 ed. São Paulo: Martins Fontes, 2002.

Submissão: 20/07/2017

Aceite: 18/11/2017 